\title{
Assessment of Diclofenac Sodium Infusion for Management of Post-Spinal Shivering
}

\author{
Sherif Sayed Sultan, Ashraf Elsayed Elagamy, Mayada Ahmed Ibrahim, Mina Magdy \\ Fakhry* \\ Anesthesia, Intensive Care and Pain Management Department, Faculty of Medicine, \\ Ain Shams University \\ *corresponding author: Mina Magdy Fakhry, E-mail: Fakhryeeee @ gmail.com
}

\begin{abstract}
Background: shivering is a common problem faced by an anesthesiologist during intraoperative as well as in postoperative period. It is a frequent, unpleasant, and undesirable complication occurring after subarachnoid block (SAB), secondary to vasodilatation as a result of sympathetic blockade. The incidence of shivering has been reported to be about $36-85 \%$ after spinal anesthesia. The present study was designed to compare the efficacy of diclofenac sodium and pethidine on reducing postoperative shivering following sub-arachnoid block.
\end{abstract}

Objectives: the aim of this study was to investigate the ability of intravenous infusion of diclofenac sodium $(1 \mathrm{mg} / \mathrm{kg}$ maximally $75 \mathrm{mg}$ ) to treat established post-spinal shivering.

Patients and Methods: after approval from departmental ethics committee in Ain shams university and written informed consent from the patient, a randomized study was conducted on ninety adult patients with American society of anesthesiologists (ASA) physical status I, II and III aged from 18 to 65 years. The study was conducted from September 2017 to February 2018. The study was a randomized, prospective, double-blind, placebo-controlled study. All patients were informed about the study design and objectives as well as tools and techniques. Informed consent was signed by every patient prior to inclusion in the study.

Results: after approval of the department of anesthesiology, intensive care and pain management at Ain Shams University ethical committee, this randomized study was conducted on ninety patients who were scheduled to have surgery with spinal anesthesia. The design of the study included three groups, each constitutes of 30 patients $(n=30)$.

Conclusion: the data showed that pethidine infusion was more effective than diclofenac sodium infusion in management of shivering after spinal anesthesia. However diclofenac sodium was better than placebo in non-significant way.

Keywords: Diclofenac Sodium Infusion, Post-Spinal Shivering, pethidine infusion

\section{INTRODUCTION}

Shivering is a frequently occurring post-anesthesia complication. It occurs after both general and regional anesthesia. It is estimated to follow more than $40 \%$ of all cases receive anesthesia. Shivering is defined as involuntary, spontaneous, oscillatory muscular activity. It is one of main cause of patient discomfort in the immediate postoperative period. Oxygen consumption increases with the intense of shivering. It may resemble a mild exercise but in some severe cases oxygen consumption may rise to $600 \%$. Postanesthesia shivering may be caused by different factors. It is considered a physiological response to core hypothermia that accompanies anesthesia. Core hypothermia is attributed mainly to redistribution of warm core blood to cold peripheral compartment after peripheral vasodilatation that starts immediately after induction of anesthesia. Other factors help hypothermia include cold room temperature and intravenous fluids used intraoperatively. Other factors that may lead to shivering include transfusion reactions, bacteremia and sepsis and drug reaction ${ }^{(1)}$.

The incidence of shivering has been reported to be about $36-85 \%$ after SAB. Shivering has detrimental effects like interference in monitoring of pulse rate, bloodpressure (BP), and ECG, increase in oxygen consumption, catecholamine secretion, carbon dioxide production, metabolic rate increase by $400 \%$, increase intraocular pressure (IOP), Intra-cranial pressure (ICP), and lactic acid 
production. Increase in heart rate, cardiac output and BP may cause problem in patient with low cardiac and pulmonary reserve ${ }^{(2)}$.

Shivering also contribute to increased wound pain, delayed healing, and delay discharge from post-anesthetic care unit. Pethidine is considered the gold standard in management of shivering but unfortunately it cause various side effect as nausea, vomiting, dizziness, sweating and feeling restless. So there is need for investigating anew drug for management of shivering with fewer side effects ${ }^{(3)}$.

\section{AIM OF THE WORK}

The aim of this study was to investigate the ability of intravenous infusion of diclofenac sodium $(1 \mathrm{mg} / \mathrm{kg}$ maximally $75 \mathrm{mg}$ ) to treat established post-spinal shivering.

\section{PATIENTS AND METHODS}

After approval from departmental ethics committee in Ain shams university and written informed consent from the patient, a randomized study was conducted on ninety adult patients with American society of anesthesiologists (ASA) physical status I, II and III aged from 18 to 65 years. The study conducted from September 2017 to February 2018.

\section{Study design and sampling}

The study was a randomized, prospective, double-blind, placebo-controlled study.

\section{Inclusion Criteria:}

- Patients aging 18-65 years of both genders.

- Patients allocated for urological, inguinal or lower limb surgeries under spinal anesthesia will be allocated for the study.

- American Society of anesthesiologist's grade-I, II and III patients who developed intra-operative shivering post spinal anesthesia.

\section{Exclusion criteria}

- Emergency surgery.

- Morbid obesity (BMI>40 Kg/m2).
- Hyper or hypothyroidism.

- Any contraindications or allergies for the study drugs.

- Hematological disorder, liver or kidney insufficiency, chronic ulcerative conditions, active gastrointestinal bleeding and bronchial asthma.

\section{Preoperative preparation}

Routine preoperative assessment was done to all patients on the day before operation; including history, clinical examination and laboratory investigations. Preoperative investigations were done according to the local protocol designed to evaluate the patients. It included hemoglobin level, hematocrit levels, blood sugar levels, serum urea, serum electrolytes, liver function tests, coagulation profile; respiratory function tests, chest radiogram and ECG. All patients were informed about the study design and objectives as well as tools and techniques. Informed consent was signed by every patient prior to inclusion in the study.

Study Interventions: Whenever the patient started to shiver, intra- or postoperatively, the patients were randomly assigned to one of three groups: diclofenac group (D group), pethidine group (P group) and control group(C group).

Diclofenac group (D group) received intravenous infusion of diclofenac sodium 1 $\mathrm{mg} / \mathrm{kg}$ (maximally $75 \mathrm{mg}$ ) diluted to $50 \mathrm{ml}$ in dextrose $5 \%$ given over 10 minutes.

Pethidine group (P group) received intravenous infusion of pethidine $0.35 \mathrm{mg} / \mathrm{kg}$ diluted to $50 \mathrm{ml}$ in dextrose $5 \%$ given over 10 minutes.

Control group ( $\mathrm{C}$ group) received intravenous infusion of dextrose $5 \%$ given over 10 minutes.

\section{Statistical Analysis}

Data were collected, revised, coded and entered to the Statistical Package for Social Science (IBM SPSS) version 23. The quantitative data were presented as mean, standard deviations and ranges when their distribution found parametric. Also qualitative variables were presented as number and percentages. 


\section{RESULTS}

Table (1): Comparison between the three studied groups as regards age and sex of the studied patients

\begin{tabular}{|c|c|c|c|c|c|c|c|}
\hline & D Group & P Group & C Group & \multirow{2}{*}{ Test value } & \multirow{2}{*}{ P-value } & \multirow{2}{*}{ Sig. } \\
\hline & & No. $=30$ & No. $=30$ & No. $=30$ & & & \\
\hline Sex & $\begin{array}{l}\text { Females } \\
\text { Males }\end{array}$ & $\begin{array}{l}6(20.0 \%) \\
24(80.0 \%)\end{array}$ & $\begin{array}{l}5(16.7 \%) \\
25(83.3 \%)\end{array}$ & $\begin{array}{l}8(26.7 \%) \\
22(73.3 \%)\end{array}$ & $0.934 *$ & 0.627 & $\mathrm{NS}$ \\
\hline Age & Mean \pm SD & $37.57 \pm 9.32$ & $39.37 \pm 9.62$ & $39.50 \pm 10.07$ & $0.374 \bullet$ & 0.689 & $\mathrm{NS}$ \\
\hline
\end{tabular}

P > 0.05 NS: Non significant; $\mathrm{p}<0.05 \mathrm{~S}$ : Significant;

*:Chi-square test; $\bullet$ : One Way ANOVA test

There were no statistically significant difference found between the three studied groups as regards age and sex of the studied patients.

Table (2): Comparison between the three studied groups as regards the duration of operation.

\begin{tabular}{|l|l|l|l|l|l|l|}
\hline $\begin{array}{l}\text { Duration } \\
\text { (hours) }\end{array}$ & D group & P group & Group & $\begin{array}{l}\text { Test } \\
\text { value }\end{array}$ & P-value & Sig. \\
\cline { 2 - 7 } Mean \pm SD $=\mathbf{3 0}$ & $1.58 \pm 0.47$ & No. $=\mathbf{3 0}$ & No. $=\mathbf{3 0}$ & $2.693 \cdot$ & 0.073 & NS \\
\hline
\end{tabular}

There were no statistically significant difference found between the three studied groups as regards time of operation with $\mathrm{p}$-value $=0.073$.

Table (3): Comparison between the three studied groups as regards response and time of response.

\begin{tabular}{|c|c|c|c|c|c|c|c|}
\hline & D group & P group & C group & \multirow{2}{*}{$\begin{array}{l}\text { Test } \\
\text { value }\end{array}$} & \multirow{2}{*}{ P-value } & \multirow{2}{*}{ Sig. } \\
\hline & & No. $=30$ & No. $=30$ & No. $=30$ & & & \\
\hline Response & $\begin{array}{l}\text { No response } \\
\text { Response }\end{array}$ & \begin{tabular}{|l}
$23(76.7 \%)$ \\
$7(23.3 \%)$
\end{tabular} & \begin{tabular}{|l}
$4(13.3 \%)$ \\
$26(86.7 \%)$
\end{tabular} & $\begin{array}{l}27(90.0 \%) \\
3(10.0 \%)\end{array}$ & $41.944^{*}$ & 0.000 & $\mathrm{~S}$ \\
\hline Time of response (min) & Mean \pm SD & $11.14 \pm 2.73$ & $9.19 \pm 2.37$ & $11.67 \pm 2.89$ & $2.674 \bullet$ & 0.084 & $\mathrm{NS}$ \\
\hline
\end{tabular}

P > 0.05 NS: Non significant., $p<0.05$ S: Significant

There were statistically significant increase in the incidence of response in $\mathrm{P}$ group in treatment of shivering than the two other groups with p-value $<0.001$ while no statistically significant difference found between the three studied groups as regards time of response with $\mathrm{p}$-value $=0.084$.

Table (4): Comparison between the three studied groups as regards the temperature at different times of measurement

\begin{tabular}{|c|c|c|c|c|c|c|}
\hline \multirow{2}{*}{$\begin{array}{l}\text { Temperature } \\
(\text { Mean } \pm \text { SD) }\end{array}$} & D group & P group & C group & \multirow{2}{*}{$\begin{array}{l}\text { Test } \\
\text { value• }\end{array}$} & \multirow{2}{*}{ P-value } & \multirow{2}{*}{ Sig. } \\
\hline & No. $=30$ & No. $=30$ & No. $=30$ & & & \\
\hline Basal & $37.41 \pm 0.09$ & $37.42 \pm 0.09$ & $37.45 \pm 0.06$ & 1.901 & 0.156 & $\mathrm{NS}$ \\
\hline After & $37.37 \pm 0.15$ & $37.42 \pm 0.09$ & $37.43 \pm 0.07$ & 2.426 & 0.094 & $\mathrm{NS}$ \\
\hline $5 \mathrm{~min}$ & $37.22 \pm 0.13$ & $37.27 \pm 0.09$ & $37.24 \pm 0.11$ & 1.651 & 0.198 & $\mathrm{NS}$ \\
\hline $10 \mathrm{~min}$ & $37.12 \pm 0.14$ & $37.17 \pm 0.15$ & $37.12 \pm 0.13$ & 1.376 & 0.258 & $\mathrm{NS}$ \\
\hline $15 \mathrm{~min}$ & $36.99 \pm 0.09$ & $37.04 \pm 0.15$ & $37.01 \pm 0.17$ & 0.840 & 0.435 & NS \\
\hline $20 \mathrm{~min}$ & $36.98 \pm 0.09$ & $37.03 \pm 0.17$ & $36.98 \pm 0.17$ & 1.210 & 0.303 & $\mathrm{NS}$ \\
\hline $25 \mathrm{~min}$ & $37.01 \pm 0.10$ & $37.12 \pm 0.16$ & $37.06 \pm 0.15$ & 4.044 & 0.021 & $S$ \\
\hline $30 \mathrm{~min}$ & $37.08 \pm 0.10$ & $37.17 \pm 0.15$ & $37.13 \pm 0.16$ & 3.695 & 0.029 & $\mathrm{~S}$ \\
\hline $35 \mathrm{~min}$ & $37.11 \pm 0.11$ & $37.22 \pm 0.13$ & $37.16 \pm 0.14$ & 5.202 & 0.007 & $S$ \\
\hline $40 \mathrm{~min}$ & $37.18 \pm 0.12$ & $37.26 \pm 0.12$ & $37.20 \pm 0.16$ & 2.735 & 0.070 & NS \\
\hline $45 \mathrm{~min}$ & $37.24 \pm 0.11$ & $37.29 \pm 0.10$ & $37.24 \pm 0.14$ & 1.764 & 0.177 & $\mathrm{NS}$ \\
\hline
\end{tabular}

There were no statistically significant difference between the three studied groups as regards temperature except at $25 \mathrm{~min}, 30 \mathrm{~min}$ and $35 \mathrm{~min}$ there were statistically significant increase in the temperature in $\mathrm{P}$ group with $\mathrm{p}$ value $=0.021,0.029$ and 0.007 respectively. 


\section{DISCUSSION}

Shivering is a common post-anesthetic complication. It is considered by some patients to be the worst experience faced during their journey from the ward through the operating theater back to the surgical ward. This unpleasant complication may interfere with the co- existing diseases making it hard to control. An example of this is patients with coronary artery disease who is faced with a status of increased oxygen consumption when the patient starts to shiver ${ }^{(2)}$.

Therefore, anti-shivering medications should be available in the operating theatre and in the post-anesthesia care unit.

An ideal anti-shivering drug is not available. Pethidine, is considered by many authors as the gold standard anti-shivering drug. It is estimated to be effective in $80 \%$ of cases ${ }^{(4)}$.

However, it carries a wide variety of side effects that affects the patient's wellbeing in the PACU. It easily transfers the patient's postoperative complication from shivering to nausea and vomiting which, in its turn, necessitates the use of a variety of anti-emetic drugs.

Pethidine easily interacts with the previously given intraoperative narcotics pushing more towards respiratory depression (5).

Unfortunately, there is no clear mechanism for any anti-shivering drug. This opens the door wide for anesthesiologists to search for a drug with anti-shivering properties to be added to the list of anti-shivering drugs. An important point comes to the view. A drug with anti- shivering properties should not be as efficient as pethidine or exceeding its efficacy. A "multi-modal" anti-shivering regimen could be used combining a group of drugs that work together to perform the job. Alternatively, a step-ladder approach in management of postanesthetic shivering could be found in the future in recent anesthesia guidelines and books.

Khezri et al. (6) investigated One hundred forty patients who were randomly allocated to two groups ( $\mathrm{n}=70$ patients for each group). Ten minutes before the induction of anesthesia, group D received Supp diclofenac $\mathrm{Na} 100 \mathrm{mg}$, and group $\mathrm{C}$ did not receive anything. Axillary temperature was measured before induction and 15 minutes after the extubation. Shivering was judged by using a three-point scale after the end of anesthesia. They reported that Diclofenac Na effectively reduced the incidence of post anesthetic shivering and it resulted in a more stable body temperature.

In the current study, shivering was noted in all patients included in the study with different grades. Pethidine was successful in abolishing post-spinal shivering in $86.7 \%$ of cases.

This is consistent with other studies like Bicer et al. ${ }^{(7)}$ who found intraoperative intravenously administration of pethidine. $0.5 \mathrm{mg} / \mathrm{kg}$ is effective in reducing post anesthetic shivering in $90 \%$ of cases.

Also, Kimberger et al. ${ }^{(8)}$ found that pethidine (target plasma level:0.9 ug/ml) reduced the shivering threshold to $34.2^{\circ} \mathrm{C}$ with mild sedation and no respiratory toxicity.

In addition, Mohta et al. ${ }^{(9)}$ who found pethidine was effective in management of post anesthetic shivering in $80 \%$ of cases.

In the present study when we compared pethidine to diclofenac sodium in management of shivering, there was statistically significant difference between diclofenac sodium group in which shivering was treated in $23.3 \%$ of patients and pethidine group in which shivering was treated in $86.7 \%$ of patient.

On the other hand, shivering was omitted in the control group in a comparable time in only $10 \%$ of cases. Although the difference between the control and diclofenac groups is clear, it did not reach significance.

The reason behind the non-significant results may lie behind one of three possibilities. Firstly; that diclofenac sodium has no anti-shivering property which was clearly evident in the suppository dose that used by Ebrahim et al. ${ }^{(10)}$. Second; is the small sample size. Third; that post-spinal shivering needs higher doses of the diclofenac sodium.

Does diclofenac sodium have antishivering property? It has anti-inflammatory properties through inhibiting prostaglandin synthesis. Diclofenac sodium was proved to reduce the production of pro-inflammatory 
cytokines such as interleukin 1 (IL-1), interleukin 6 (IL-6) and tumor necrosis factor (TNF) ${ }^{(11)}$. The reduction of cytokines is one mechanism of other drugs succeeded in reducing incidence of shivering ${ }^{(12)}$. Moreover, diclofenac sodium is able to inhibit hypothermia which is a major factor in initiating post-anesthetic shivering ${ }^{(13)}$. Horn et al. ${ }^{(14)}$ stated that postoperative pain facilitates non-thermoregulatory shivering. Therefore, any drug with analgesic properties may have anti-shivering property.

Does the post-spinal shivering need a higher dose of diclofenac sodium to be better treated? In the current study we used the dose of $1 \mathrm{mg} / \mathrm{kg}$ with a maximum of $75 \mathrm{mg}$. This dose was used by Campbell and Waters ${ }^{(15)}$, Voilley et al. ${ }^{(16)}$ and Jimenez et al. ${ }^{(17)}$. We could not give a higher dose for the fear of theoretical complication of increasing the possibility of postoperative bleeding. However, more studies are needed to test higher doses of the tested drug.

Answering the previous three questions may conclude our work. Diclofenac sodium may have a role as an anti-shivering drug. A study with larger sample size is needed. However a higher dose of diclofenac sodium may be used to check its efficacy in reducing post spinal shivering. This should be done in a controlled study to be able to check for increasing possibility of post-operative bleeding.

\section{CONCLUSION}

In this study, the data show that pethidine infusion is more effective than diclofenac sodium infusion in management of shivering after spinal anesthesia. However diclofenac sodium is better than placebo in anon significant way. Another study with larger sample size and higher dose of diclofenac sodium is needed to check the efficacy of the diclofenac sodium as antishivering drug.

\section{REFERENCES}

1. Bansal P and Jain G (2011): Control of shivering with Clonidine, butorphanol, and Tramadol under Spinal anesthesia: a comparative study. Local and Regional Anesthesia, 4:29-34.

2. Shukla U, Malhotra K, Prabhakar TA (2011): Comparative study of the effect of clonidine and tramadol on post-spinal anaesthesia shivering. Indian Journal of Anaesthesia, 55(3):242-6.

3. Abdelrahman RS (2012): Prevention of shivering during regional anaesthesia: Comparison of Midazolam, Midazolam plus ketamine, Tramadol, and Tramadol plus Ketamine. Life Science Journal, 9(2):13-29.

4. Mokhtarani M, Mahgoub AN, Morioka N (2001): Buspirone and meperidine synergistically reduce the shivering threshold. Anesth Analg., 93:12331239.

5. Kurz M, Belani K, Sessler DI et al. (1997): Naloxone, meperidine, and shivering. Anesthesiology, 79:1193201.

6. Khezri MB, Bandari AM, Asefzade S, Atlasbaf A (2011): The effect of diclofenac $\mathrm{Na}$ supp on postoperative shivering in patients undergoing elective cesarean section surgery. Pak J Med Sci., 27(5):1145.

7. Bicer C, Esmaoglua, Akin A, Boyaci A (2006): Dexmedetomidine and meperidine prevent postanaesthetic shivering.Anaesthesiol., 23(2):149-53.

8. Kimberger $\mathbf{O}$, Markstaller Z, Lauber $\mathbf{R}$ and Kru A (2007): Compination of pethidine and skin warming reduced the shivering threshold to $33 " 8 \mathrm{c}$ with very mild sedation and no respiratory toxicity critical care journal, 11(1):R29.

9. Mohta M, Kumari N, Tyagi A et al. (2009): Tramadol for the prevention of post anaesthetic shivering: a randomised double blind comparison with pethidine Anaesthesia, 64 (2): 141-6.

10. Ebrahim AJ, Mozaffar R, Nadia BH (2014): A single dose of diclofenac sodium supp can provide satisfactory analgesia and decrease shivering without markable complication. Anesthesiol Clin Pkarmaco., 30(2):243-7.

11. Osnes LT, Foss KB, Joo GB et al. (1996): Acetylsalicylic acid and sodium salicilate inhibit LPS-induced NF-kappa B / c-Rel nuclear translocation, and synthesis of tissue 
factor (TF) and tumor necrosis factor alpha (TNF-alpha) in human monocytes. Thromb. Haemost., 76: 970-976.

12. Yared JP, Starr NJ, Hoffman-Hogg L, Bashour CA, Insler SR, O'connor M, Piedmonte M, Cosgrove DM (1998): Dexamethasone decreases the incidence of shivering after cardiac surgery: a randomized, double-blind, placebo-controlled study. Anesthesia \& Analgesia, 87(4):795-9.

13. Dogan MD, Ataoglu H, Akarsu ES (2002): Characterization of the hypothermic component of LPSinduced dual thermoregulatory response in rats. Pharmacol. Biochem. Behav., 72: 179-185.

14. Horn EP, Sessler DI and Standl T (1998): Non thermoregulatory shivering in patients recovering from isoflurane or desflurane anesthesia, Anesthesiology, 89: $878-86$.

15. Campbell $W$ and Watters $C$ (1991): Venous sequelae after iv diclofenac. British Journal of Anaesthesia, 67(6):803.

16. Voilley $\mathbf{N}$, de Weille $J$, Mamet $J$, Lazdunski M (2011): Nonsteroid anti-inflammatory drugs inhibit both the activity and the inflammationinduced expression of acid-sensing ion channels in nociceptors. J Neurosci., 21(20):8026-33.

17. Jimenez D, Bikedi B, Barrios D et al. (2018): Patterns of care for patient with acute pulmonary embolism, Int $\mathbf{J}$ Cardiol., 51(5):101-183. 